\title{
Event review: International Knapping Workshop, with Bruce Bradley, Fazenda Monte Alto, Dourado, SP (Brazil)
}

\author{
Elisa van Veldhuizen ${ }^{1}$ and João Carlos Moreno de Sousa ${ }^{2}$ \\ 1. Leiden University, Faculty of Archaeology. Einsteinweg 2, 2333 CC Leiden, Netherlands. \\ Email: e.t.a.van.veldhuizen@umail.leidenuniv.nl \\ 2. PPGArq, National Museum, Federal University of Rio de Janeiro. Quinta da Boa Vista, s/n, Säo Cristóvão, \\ Rio de Janeiro, RJ. Brazil. Email: jcmorenodesousa@usp.br
}

The event took place from 3 till 8 July 2016 at Fazenda Monte Alto, Dourado, SP, Brazil. The aim of the course was to provide intensive knapping training in order to enhance analytical methods and procedures. This training was not only for students, but also professionals who were interested in the course. The course was given by Bruce Bradley (University of Exeter), who has extensive experience with Stone Age technologies and experimental archaeology. Mercedes Okumura (PPGArq, National Museum, Federal University of Rio de Janeiro) and Astolfo G. M. Araujo (Museum of Archaeology and Ethnology, University of São Paulo) organized the course, which was sponsored by Fazenda Monte Alto, Café Helena, and the British Academy, Newton Mobility Grants Scheme (NG140077). The workshop had 15 participants from Brazil, Uruguay, the Netherlands and Canada (Figure 1).

Each day a new subject was covered. Starting the first day with a morning class about the basics of knapping - what was needed to control the fracturing of stones; what types of stones are useful for knapping (as core, blank or hammerstone) according to their features; the angles for hitting stone; and the force of impact. After the class students tried the basics out themselves on local raw materials - average to high quality silicified sandstone - using quartz pebbles as hammerstones. They worked in pairs so there was someone to help the knapper with the right movement and monitor safety precautions (which included wearing safety glasses and using pieces of leather). The first task was to produce flakes from a core by working from the farthest point to the middle of the platform (Figure 2) and to learn to predict knapping results - shape and size of the flake - before hitting the platform. Comparing predictions to results allowed students to see what happened and learn more about the behaviour of fracturing. Discussions also included the importance of cleaning the area after knapping so as not to create what someone might later believe is an archaeological site. It should be noted that the knapping area of the course was on a modern, man-made feature, with no archaeological sites in the vicinity. ISSN: 2055-0472. URL: http://journals.ed.ac.uk/lithicstudies/

This work is licensed under a Creative Commons Attribution 2.5 UK: Scotland License. 


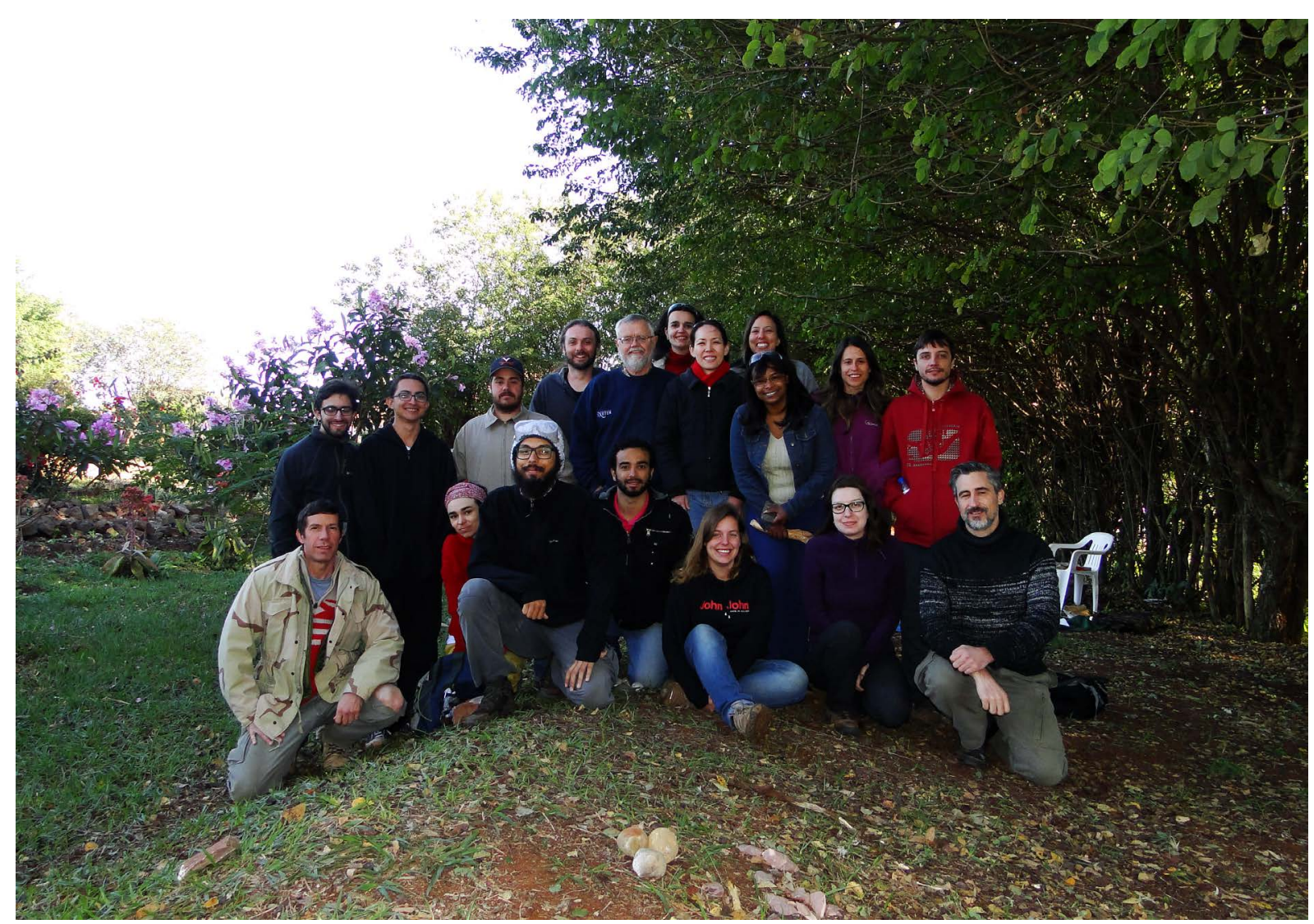

Figure 1. The Participants and organizers of the workshop. (Photograph by Astolfo G. M. Araujo, 2016.)

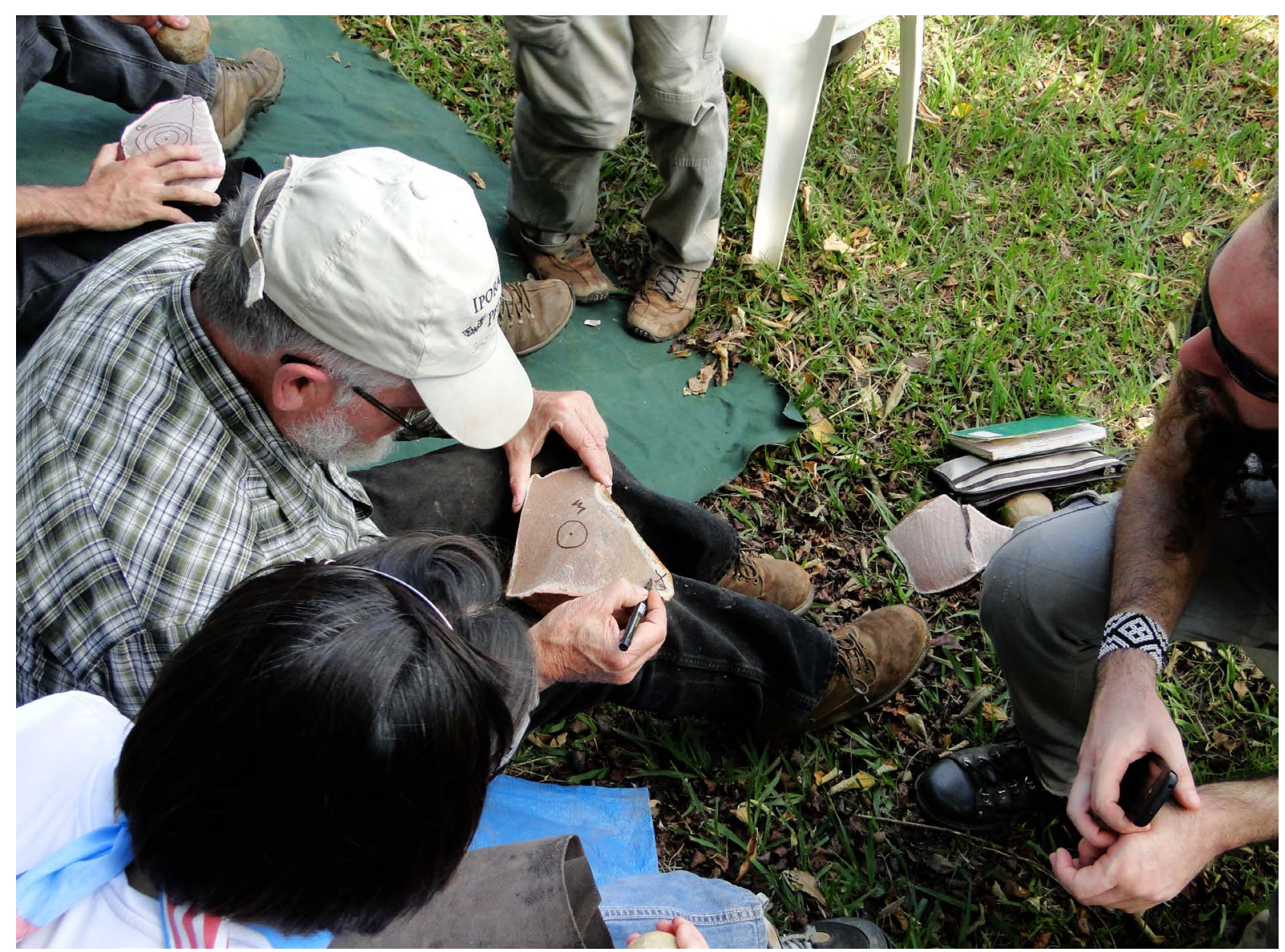

Figure 2. Bruce Bradley explaining the first task and technique. (Photograph by Astolfo G. M. Araujo, 2016.) 
The second day introduced the students to the production of unifacial tools, using the Brazilian Paleoindian limace as a model, and using the same cores produced the first day, turning them into blanks for the tool. This class let the students practice not just predicting the flakes, but also predicting the final shape and size of the tool, while still following the same rule about knapping from the farthest point to the middle to avoid breaking the tool. Several times people encountered what happens when not following the rule but by the end of the day all of the students were successfully in producing tools.

The third day introduced bifacial knapping. One of the most important lessons learned in this class was how bifacial knapping can be more difficult and complex in comparison to unifacial knapping. Some demonstrations were made by the instructor, in order to show some of the variability of methods and techniques that may be followed for the production of bifacial tools, such as bifacial thinning. Students were encouraged to continue predicting the flakes and the final shape and size of the end tool, but now also thinking that every flake removed from one face affected the opposite platform as well.

During the workshop, Dr. Bradley gave two evening presentations. The first was 'AUKward Proposal, Evidence of a trans-Atlantic contribution to the Ice Age peopling of the Americas' was about his research on Pre-Clovis and Clovis Technology, Solutrean Technology and the hypothesis of the movement of people between Europe and North America during Late Pleistocene. The second was 'Integrated Problem-oriented Experimental Archaeology: An example from the French Upper Palaeolithic', which show how controlled experimental knapping can help in understanding the archaeological record and can improve the archaeological methods used in excavations as well in analysing materials.

The morning of fourth day involved a survey to find blocks of raw material for knapping. This activity looked at how to choose good raw material for knapping. Afterwards, students had time for more unifacial and bifacial knapping practice (Figure 3).

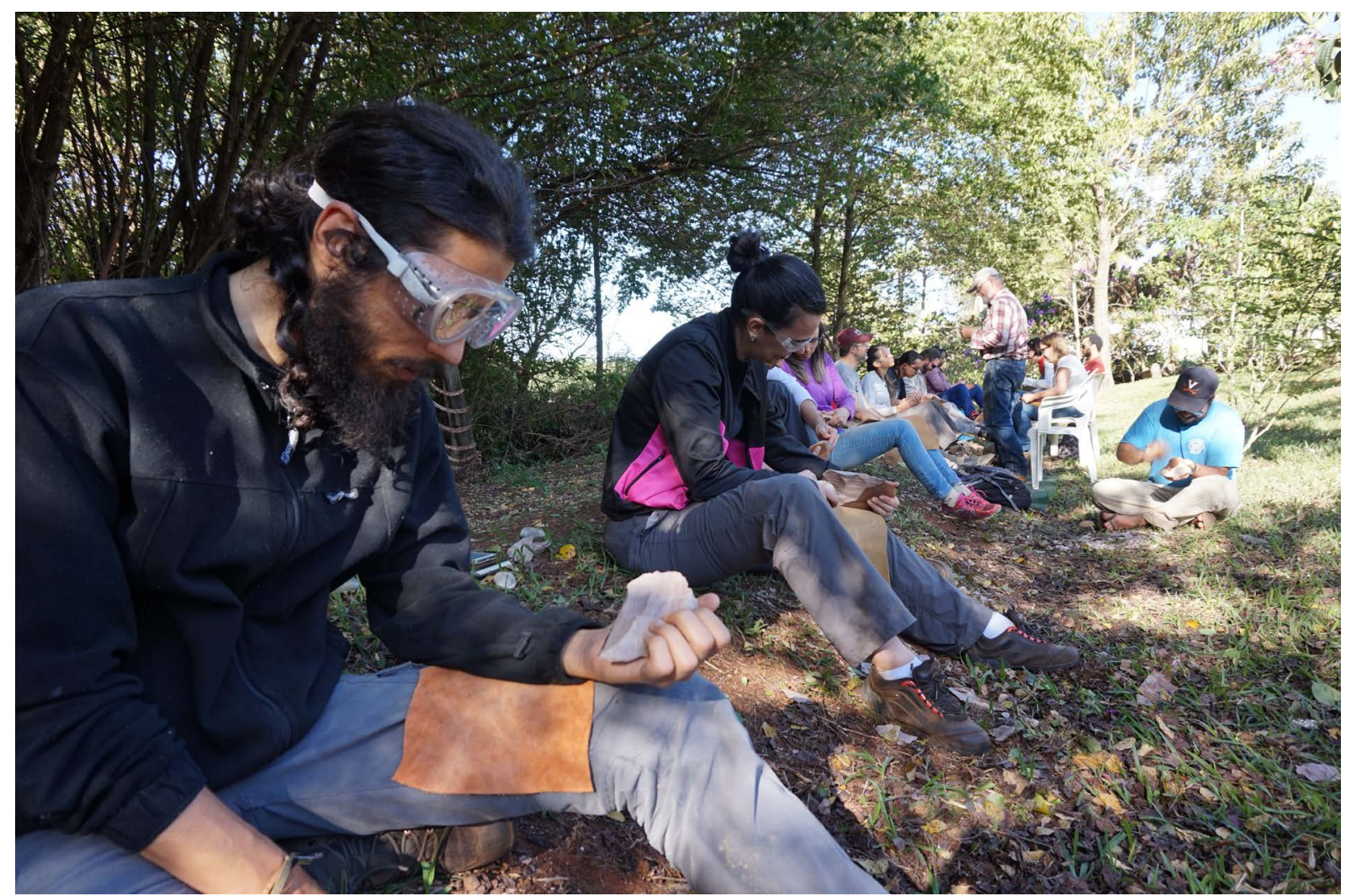

Figure 3. Participants of the workshop practicing unifacial and bifacial knapping. (Photograph by Nicolás Batalla, 2016.) 
On the fifth day the topic of the class was blade technology, in order to understand more about blade cores in archaeological settings and how blade technology is different from flakes with blade shape. After this class, the group visited the Bastos archaeological site, to take a look at the surface lithic remains and to compare them to the local raw materials and to the tools and debitage from the knapping classes. The afternoon continued general knapping practice.

The last day looked at pressure knapping, in particular, how this technique can be used not just for shaping the edges of the tools and producing bladelets, but also producing bigger blades depending on the pressure. This part of the course involved the use of higher quality raw materials, some of them having been heat-treated. During this class, students also tried soft hammer percussion with antlers.

The course was a great opportunity for researchers and university students focused on lithic studies. In many countries, including Brazil, workshops like these, where everyone is able to practice instead of just having theoretical classes, are often rare. It is exceptional in the sense that everyone could apply the things they learned directly by knapping themselves. As well, this course provided many students with a new and more complete view of archaeological remains - not only studying the archaeological artefacts but also understanding how those artefacts were produced. Hopefully, this event will encourage more researchers with broad experience in lithic studies and knapping to provide practical workshops like this, and also to stimulate archaeology institutes to invite more researchers to give similar types of workshops. 